\section{Nauplius}

THE JOURNAL OF THE Brazilian Crustacean Society

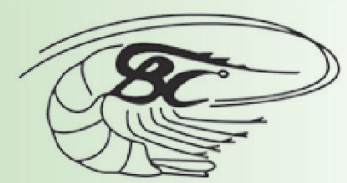

e-ISSN 2358-2936

www.scielo.br/nau www.crustacea.org.br

\title{
Drawing setae: a GNU way for digital scientific illustrations
}

\author{
Giuseppe Montesanto
}

Dipartimento di Biologia, Università degli Studi di Pisa, via A. Volta 4bis, 56126, Pisa, Italy. ORCID ID http://orcid.org/0000-0001-8946-1185

ZOOBANK http://zoobank.org/urn:lsid:zoobank.org:pub:7A395300-9651-4D1F93ABACEBA28E7CFC

\section{Abstract}

In a recent paper (2015) I proposed a method to draw accurate line drawings for taxonomic studies, using taxa from Oniscidea. To complement that work, this short communication proposes a free-hand way to quickly draw areas with small setae or hairs, such as in penicils of mouth parts. This method enhances the previous drawing procedure, it takes a brief practice time, and allows a better quality of scientific illustrations.

\section{KEY WORDS}

GIMP, crustaceans, Isopoda, Oniscidea, taxonomy, drawings, setae.

Crustaceans show a wide range of cuticular projections that are ordinarily called setae, although many terms indicate the same structures: sensilla, bristles or even 'hairs'. There are also some other definitions for these structures and they are generally meant to be homology-based (Garm, 2004). As a matter of fact, setae can be divided into different types according to their mechanical functions. Garm (2004) defined setae based on their mechanical functions rather than homology.

Crustacean taxonomists, as well as other arthropod taxa specialists, have devoted considerable time of their valuable work in drawings to illustrate species. During the last decade, Dr. Charles O. Coleman (Museum für Naturkunde, Berlin, Germany) strongly contributed on improving methods and techniques used in this interesting field of taxonomy (Coleman, 2003; 2006; 2009).

I have recently proposed a new method to speed up the process of digital illustration and to produce accurate line drawings starting from pencil drawings or microphotographs. This method (Montesanto, 2015), exclusively based on raster graphics, uses a completely free software (GNU Image Manipulation Program, GIMP). It is ordinarily used by myself and other colleagues to illustrate species (e.g. figures 1-5 in Montesanto et al., 2011; figures 6, 7, and 9 in Montesanto et al., 2012; figure 2 in Agodi et al., 2015) and other figures, such as maps, dendrograms, graphs and diagrams (e.g. Medini-Bouaziz et al., 2006; Montesanto et al., 2007; 2008; 2014; Messina et al., 2011; 2012; 2014; Lupetti et al., 2013).

CORRESPONDING AUTHOR Giuseppe Montesanto giuseppe.montesanto@unipi.it

SUBMITTED 27 May 2016 ACCEPTED 12 August 2016 PUBLISHED 20 October 2016

DOI 10.1590/2358-2936e2016017 
I have mainly worked with the taxon Oniscidea (terrestrial isopods); in this group, some body parts show areas with several small setae or fine hairs. Buccal appendages, such as mandibles and maxillulae, generally bear penicils entirely covered by fine setae that are not easy to draw without a great waste of time.

Therefore, to complement the previously cited work (Montesanto, 2015), I here propose a free-hand way to quickly draw small setae with a single movement of the mouse.

\section{Method}

GIMP version 2.8.14 on a Mac Mini, late 2013, with Mac OS 10.11.5, has been used. GIMP workspace and settings are the same as described in Montesanto (2015), as shown in Fig. 1.

Once the file is opened, the settings in the Tool Options window of the Paintbrush Tool need to be changed in order to set the brush preferences (Fig. 2).

\section{Step-by-step instructions}

In order to easily draw a perfect seta with a natural appearance, the user needs to add a dynamic to the brush. Dynamics are quite often used by artists who work with digitizer boards or digital graphic pens. In our case a basic dynamic will be added to a simple mouse movement, with the following instructions:

- choose the Paintbrush Tool in the Toolbox (Fig. $1 \mathrm{~F})$;

- choose the appropriate brush: N. 2. Hardness 075 (the same in Montesanto, 2015);

- left click on the "Dynamics" button in the Tool Options panel (Fig. 2A);

- choose "Basic Dynamics" from the menu;

- in the "Fade Options" bar, choose a value from 50-90, depending of the length of the seta that should be drawn (see after) (Fig. 2B);

- set the "Reverse" option as active (Fig. 2C);

- the remaining options can be left with default values (as shown in Fig. 2).

\section{How to draw a small seta}

Each seta is drawn by pressing the left mouse button and, simultaneously, moving fast the mouse toward the direction of seta tip. The mouse button is to be released in the exact point where the seta tip should be drawn.

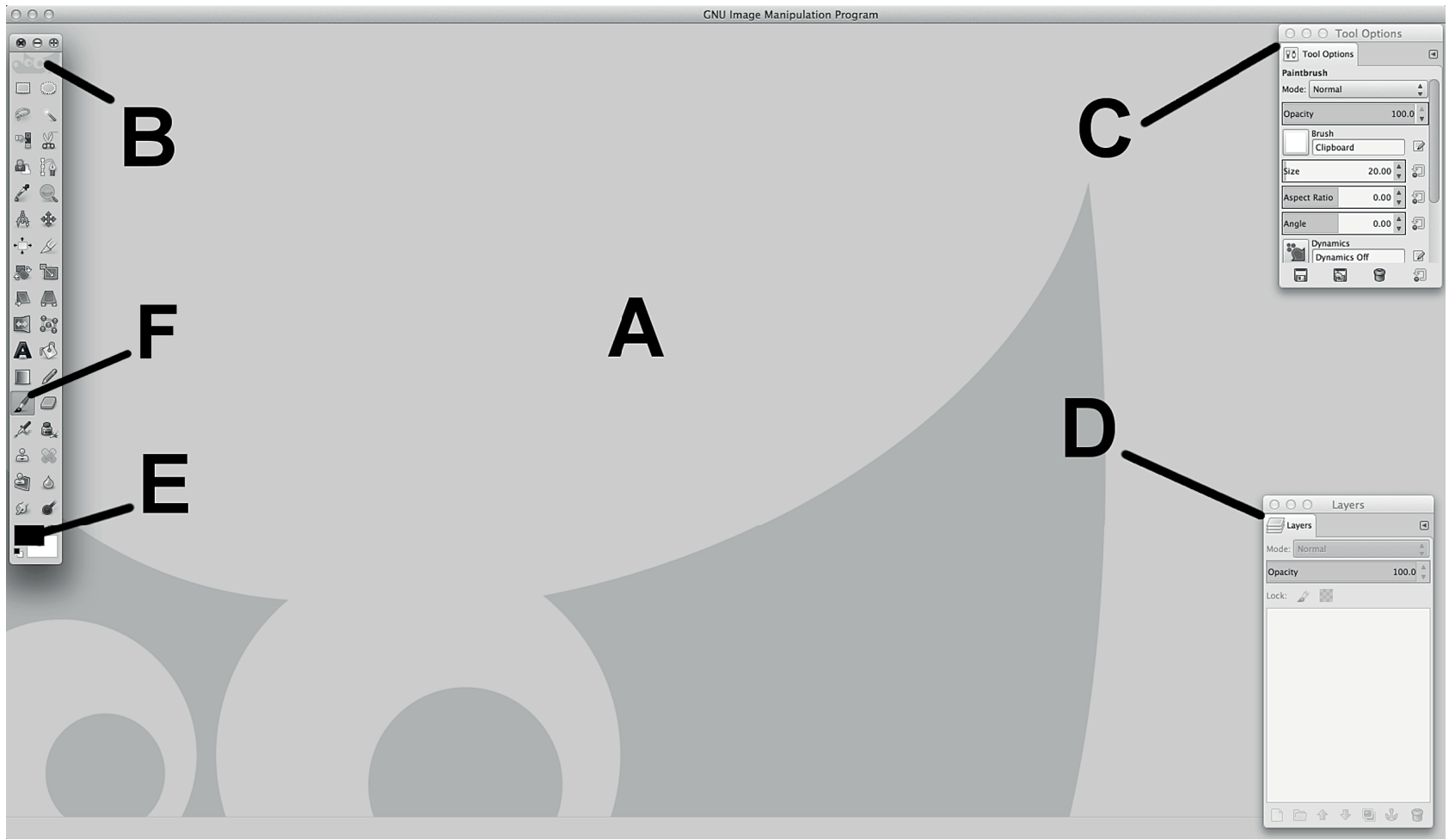

Figure 1. Screenshot of GNU Image Manipulation Program (GIMP, ver. 2.8.14) on a Mac OS. A, Image window; B, Toolbox window; C, Tool Options window; D, Layers window; E, Foreground (black) and Background colours (white); F, Paintbrush Tool. 


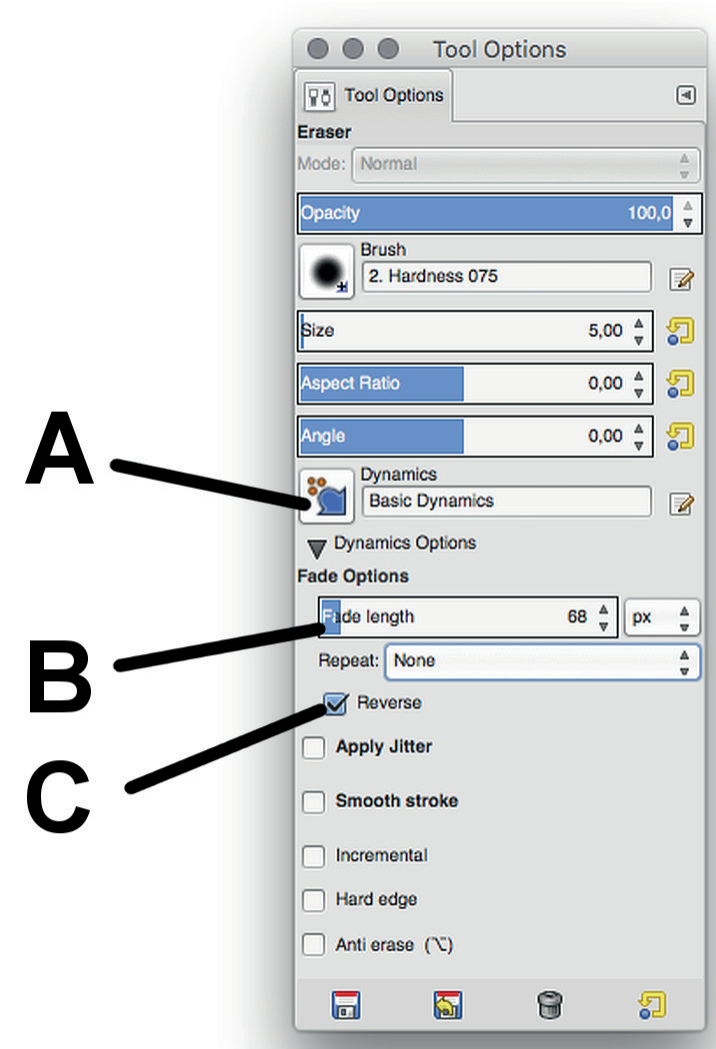

Figure 2. Screenshot of the Tool Options window, with Paintbrush Tool activated. All the settings should be as shown; brush size can be modified accordingly to the line drawings.
It's important to move the mouse quite quickly. If the movement is too slow the line will just appear as a shade of grey but with no smaller dimension in the apex. If it is sufficiently fast the user can also observe how the tip tends to be reduced in size (Fig. 3A, B). After the first attempts it will become a natural and repetitive movement, and the right balance between the speed of mouse and the fade length will be easily found.

Fade Options is particularly important as it determines the length of the fading and therefore the actual length of the seta; its base width is the brush size, which should follow the line of the existing image. Thus, a line drawing made with a 6 pixels brush, should have setae drawn with a smaller brush (e.g. size: 3 pixels). Usually, a brush size of 3-5 pixels would be the right choice for most of the line drawings. An example of setae drawn with different brush size is reported in Fig. 3C. It is also important to draw setae using the maximum viewing zoom level; good examples are $400 \%$ or even better $800 \%$. Then, image visualization can be shifted on the screen by pressing the space bar on the keyboard and dragging the mouse. Examples of drawings of setose (or hairy) areas in isopod appendages using the present technique are shown in Fig. 4.

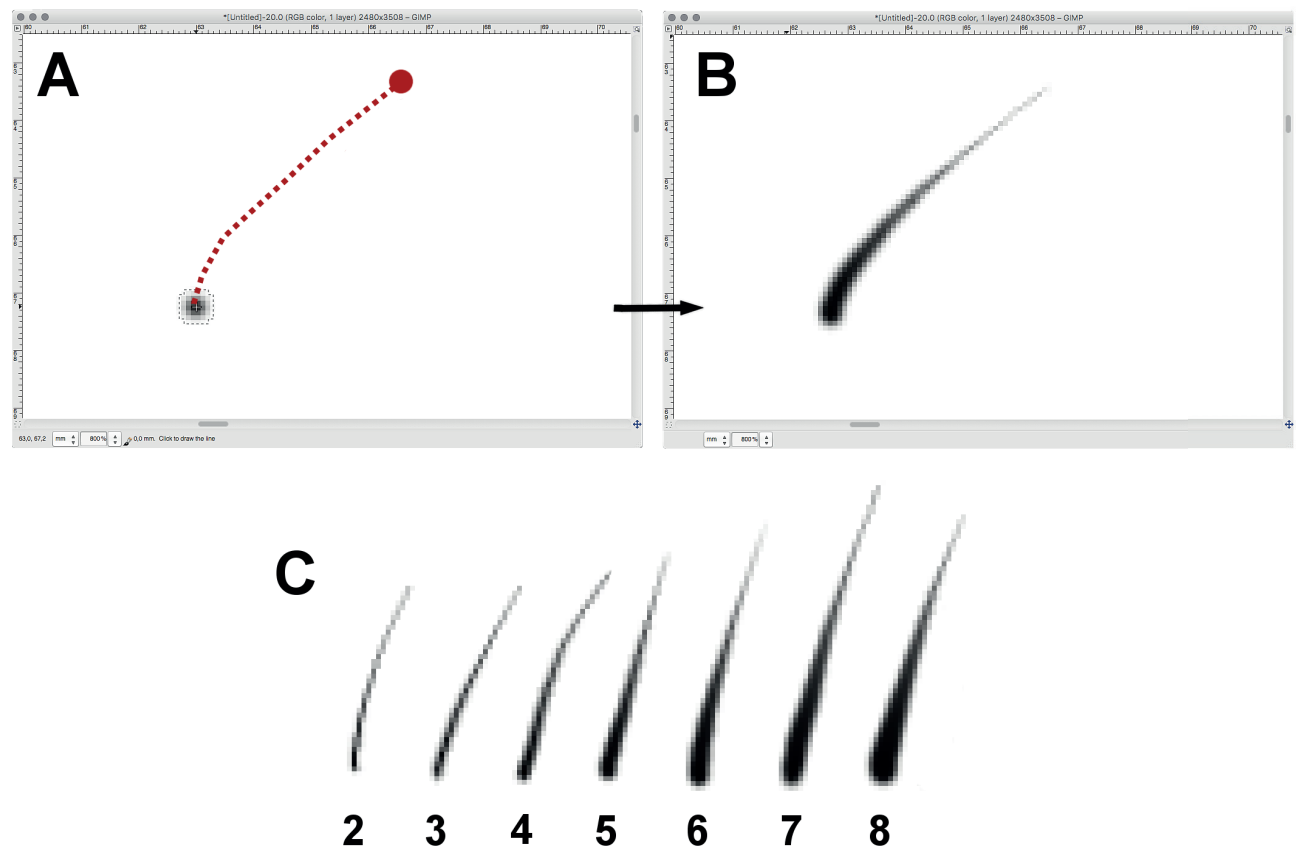

Figure 3. Visual explanation on how to draw a single small seta. A, grey circle indicates the starting point (click and keep the left mouse button pressed); then, move fast the mouse to the direction shown by the red dotted line; the red circle indicates the releasing position of the mouse button. B, obtained result. C, examples of result using different brush sizes (2-8 pixels). 

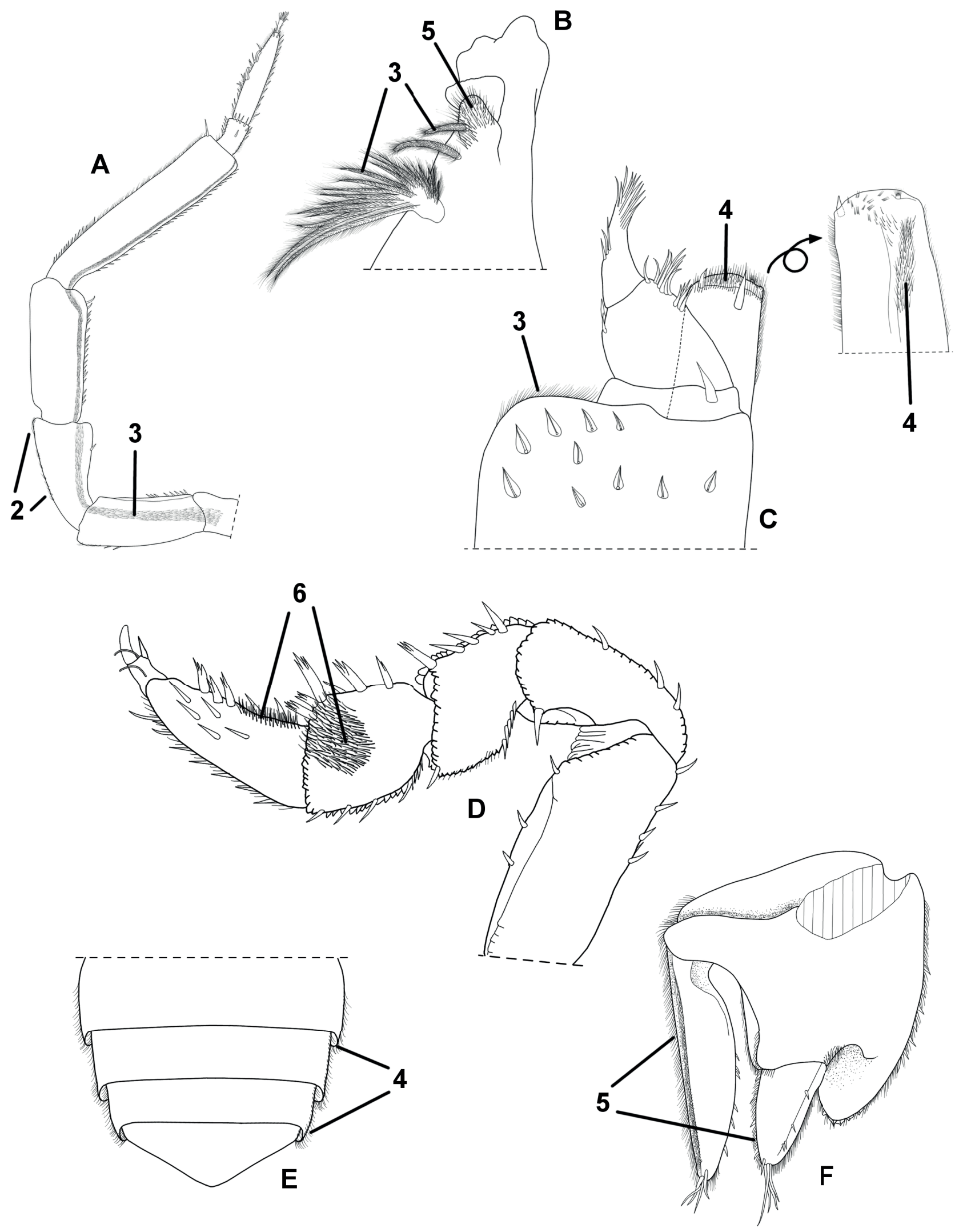

Figure 4. Examples of line drawings of terrestrial isopods anatomical parts. Areas with small setae drawn with the present method are indicated with a black line. Numbers indicate brush size. A, antenna; B, right mandible; C, maxilliped; D, pereopod 1; E, telson; F, uropod. 
Further information could be retrieved in the GIMP documentation website (https://docs.gimp.org/), or asked directly to the author.

\section{DISCUSSION}

In his short paper, Coleman (2009) commented that the free-hand method is one of three possible ways to draw setae. As reported by the author, the advantage is that it is possible to draw every shape of seta or spine; but the disadvantages are the waste of time and the imperfect lines, especially for the tip of the seta. Other details were also shown in Coleman (2003).
In my opinion, the presented method brings an enhancement to the previous drawing procedure (Montesanto, 2015). Figure 5 clearly shows differences in drawing setae with the present method. Stronger and/or single setae should be drawn following the technique in Montesanto (2015).

This method is very easy to use, takes little practice time, and allows a better quality of scientific illustrations. Moreover, it is completely free as it uses open source software and commonly used devices. Further details (e.g. about saving the files or exporting the plates) may be found in Montesanto (2015) or directly requested to the author.

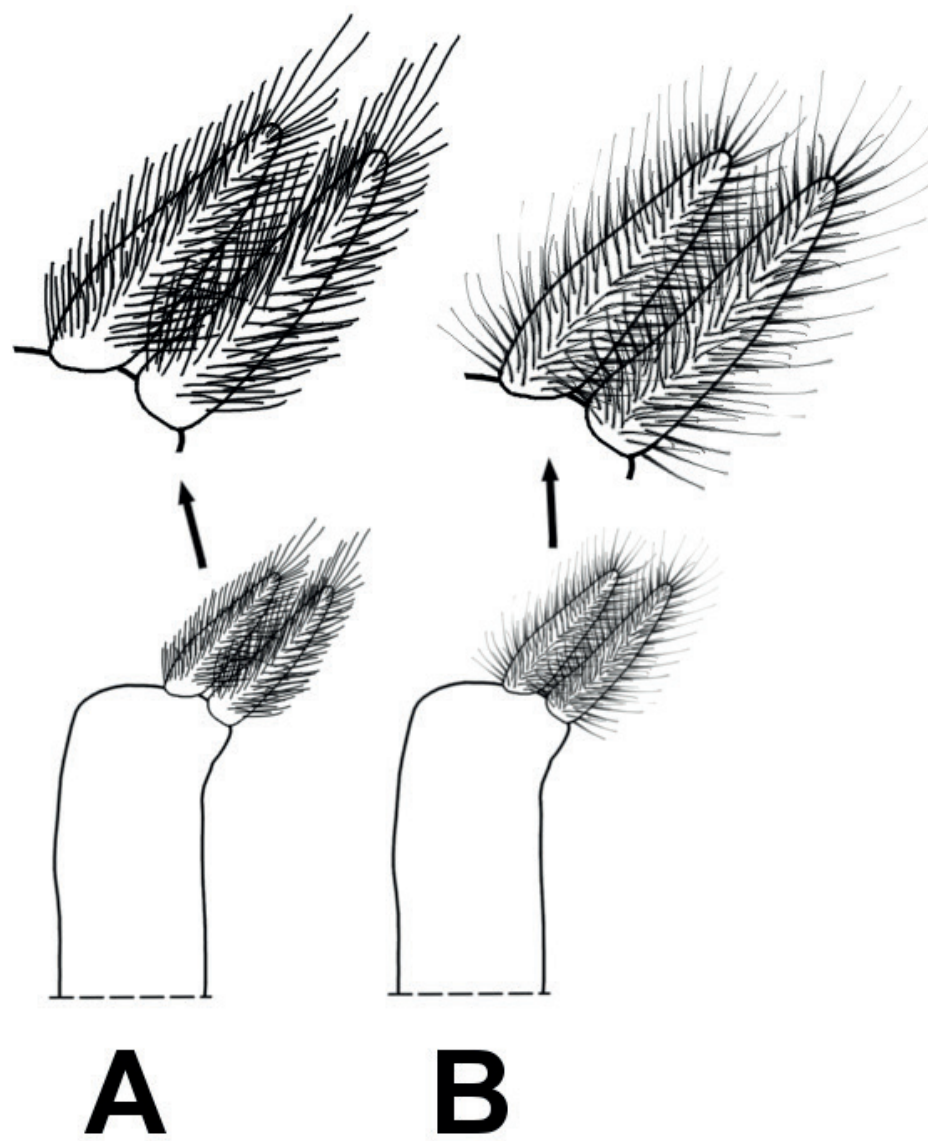

Figure 5. Example of a small setae area in a terrestrial isopod species: penicils of a maxillula inner branch. A, drawn with Montesanto method (2015); B, drawn with the method presented here. Brush size is the same (3 pixels) but setae appear more realistic with the second method.

\section{ACKNOWLEDGEMENTS}

I would like to express my very great appreciation to Dr. Annamaria Pulina (University of Pisa, Italy) for her noteworthy contribution in the revision of English. Many thanks to Dr. Stefano Taiti (ISE-CNR, Florence, Italy) for his endless constructive comments and precious advice about drawing and preparing plates for terrestrial isopod taxonomy, and also for his precious suggestions in the early version of this paper. A special acknowledgement goes to Prof. Paula B. Araujo (Universidade Federal do Rio Grande do Sul, Porto Alegre, Brasil) for encouraging me in the proposal of this short contribution. I would like to thank Dr. Charles Oliver Coleman (Museum für Naturkunde, 
Berlin, Germany) and an anonymous reviewer for their valuable comments which helped to improve the manuscript.

\section{References}

Agodi, A.; Oliveri Conti, G.; Barchitta, M.; Quattrocchi, A.; Lombardo, B.M.; Montesanto, G.; Messina, G.; Fiore, M. and Ferrante, M. 2015. Validation of Armadillo officinalis Dumèril, 1816 (Crustacea, Isopoda, Oniscidea) as a bioindicator: In vivo study of air benzene exposure. Ecotoxicology and Environmental Safety, 114: 171-178.

Coleman, C.O. 2003. "Digital inking”: How to make perfect line drawings on computers. Organisms Diversity and Evolution, 3(4): 303-304.

Coleman, C.O. 2006. Substituting time-consuming pencil drawings in arthropod taxonomy using stacks of digital photographs. Zootaxa, 1360: 61-68.

Coleman, C.O. 2009. Drawing setae the digital way. Zoosystematics and Evolution, 85(2): 305-310.

Garm, A. 2004. Revising the definition of the crustacean seta and setal classification systems based on examinations of the mouthpart setae of seven species of decapods. Zoological Journal of the Linnean Society, 142(2): 233-252.

Lupetti, P.; Montesanto, G.; Ciolfi, S.; Marri, L.; Gentile, M.; Paccagnini, E. and Lombardo, B.M. 2013. Iridovirus infection in terrestrial isopods from Sicily (Italy). Tissue and Cell, 45(5): 321-327.

Medini-Bouaziz, L.; Montesanto, G.; Charfi-Cheikhrouha, F.; Caruso, D. and Lombardo, B.M. 2006. Genetic and morphological analysis of Tunisian populations of Porcellio variabilis Lucas. Italian Journal of Zoology, 73(2): 1-6.

Messina, G.; Montesanto, G.; Pezzino, E.; Caruso, D. and Lombardo, B.M. 2011. Diversity of terrestrial isopods in a protected area characterized by salty coastal ponds (Vendicari, Sicily). Journal of Natural History, 45(35-36): 2145-2158.
Messina, G.; Montesanto, G.; Pezzino, E.; Sciandrello, S.; Caruso, D. and Lombardo, B.M. 2014. Plant communities preferences of terrestrial crustaceans (Isopoda: Oniscidea) in a protected coastal area of southeastern Sicily (Italy). Biologia, 69(3): 354-362.

Messina, G.; Pezzino, E.; Montesanto, G.; Caruso, D. and Lombardo, B.M. 2012. The diversity of terrestrial isopods in the natural reserve "Saline di Trapani e Paceco" (Crustacea, Isopoda, Oniscidea) in northwestern Sicily. ZooKeys, 176: 215-230.

Montesanto, G. 2015. A fast GNU method to draw accurate scientific illustrations for taxonomy. ZooKeys, 515: 191-206.

Montesanto, G.; Caruso, D. and Lombardo, B.M. 2007. Taxonomic status of the Mediterranean terrestrial isopod Porcellio lamellatus Budde-Lund as inferred from genetic and morphological differentiation (Crustacea, Isopoda, Oniscidea). Crustaceana, 80(8): 917-938.

Montesanto, G.; Caruso, D. and Lombardo, B.M. 2008. Genetic variability in parthenogenetic and amphigonic populations of Platyarthrus aiasensis from Sicily (Crustacea, Isopoda, Oniscidea). In: M. Zimmer; F. Charfi-Cheikhrouha and S. Taiti (eds), Proceedings of the international symposium on terrestrial isopod biology: ISTIB-07. Aachen, Shaker, 59-67.

Montesanto, G.; Caruso, D. and Lombardo, B.M. 2011. A new species and new records of terrestrial isopods from Sicily (Isopoda: Oniscidea). Journal of Natural History, 45(31-32): 1925-1935.

Montesanto, G.; Deidun, A.; Scibberas, A.; Scibberas, J. and Lombardo, B.M. 2014. Current distribution of two species of Tylos (Isopoda: Oniscidea) in the Central Mediterranean and the influence of beach sand grain-size parameters. Journal of Crustacean Biology, 34(1): 47-53.

Montesanto, G.; Musarra Pizzo, G.; Caruso, D. and Lombardo B.M. 2012. The postmarsupial development of Porcellio siculoccidentalis, with some data on reproductive biology (Crustacea, Isopoda, Oniscidea). ZooKeys, 176: 87-101. 